\title{
Synthesis of Highly Purified Tetramethylammonium Hydroxide Solution
}

\author{
Osamu YAGI* and Shumpei SHIMIZU \\ Received August 17, 1995 ; Accepted November 28, 1995
}

\begin{abstract}
Tetramethylammonium hydroxide (TMAH) solution, which was free from chloride ion, was synthesized by electrolysis of the corresponding formate and hydrogencarbonate salts in an electrolytic cell with a cation exchange membrane. When the formate salt was used as an intermediate of TMAH synthesis, the TMAH solution was contaminated by a small amount of formic acid. More purified ТМAH solution was obtained, upon using the hydrogencarbonate salt as an intermediate. Reaction of trimethylamine and dimethyl carbonate reacted in an equivalent molecular ratio suggested that one of the two methyl groups of dimethyl carbonate was incorporated into the methyl carbonate salt. Electrolysis of the hydrogencarbonate solution which was free from methanol by hydrolysis of the methyl carbonate salt provided the corresponding TMAH solution with a high current efficiency in the electrolytic cell with a cation exchange membrane as a diaphragm. Counter anions of tetramethylammonium salts affected current efficiency, and a sufficient result was obtained with hydrogencarbonate among such anions examined as sulfate, chloride, and formate salts. The current efficiency decreased more prominent with stronger acids in the anolyte. It was suggested that the important factor to affect the current efficiency was $\mathrm{pH}$ of the anolyte. All contaminants of metallic ions were less than $10 \mathrm{ppb}$, and the concentration of carbon dioxide was less than $10 \mathrm{ppm}$.
\end{abstract}

\section{ImTroduction}

Tetramethylammonium hydroxide (TMAH) 1 is an organic base as strong as $\mathrm{NaOH}$ or $\mathrm{KOH}$. TMAH has two distinguishing properties; one is decomposable at $135-140^{\circ} \mathrm{C}^{1)}$ which leaves no decomposition residue, and the other free from inorganic ions.

As for the latter property, it is widely used in developing and washing processes of semiconductor production. ${ }^{2)}$ Recently, semicon ductors have been integrated more densely, and this progress requires higher purity of TMAH. ${ }^{3)}$

To date, TMAH $\underline{1}$ has been produced by an electrolysis of quarternary ammonium chloride $\underline{4}$ in an electrolytic cell equipped with a cation exchange-membrane as a diaphragm as shown in

Tama Chemicals Co., Ltd. (3-22-9 Shiohama Kawasaki-ku Kawasaki 210, Japan)

Key Wards: TMAH, Developer, Electrolys is
Scheme 1. ${ }^{4)}$

$$
\begin{aligned}
& \begin{array}{ccc}
\left(\mathrm{CH}_{3}\right)_{3} \mathrm{~N}+\mathrm{CH}_{3} \mathrm{Cl} & \left.\underset{2}{\stackrel{\mathrm{CH}_{3} \mathrm{OH}}{\longrightarrow}} \underset{\underline{3}}{(} \underset{3}{\left(\mathrm{CH}_{3}\right)}\right)_{4} \mathrm{~N}^{+} \mathrm{Cl}^{-}
\end{array} \\
& \underline{4}+\mathrm{H}_{2} \mathrm{O} \stackrel{\mathrm{e}^{-}}{\longrightarrow}\left(\mathrm{CH}_{3}\right){ }_{4} \mathrm{~N}^{+} \mathrm{OH}^{-}+1 / 2 \mathrm{Cl}_{2}+1 / 2 \mathrm{H}_{2} \\
& 1 \\
& \text { Scheme } 1
\end{aligned}
$$

In this method, an exchange-membrane does not completely inhibit the permeation of chlorine and chloride ion into a catholyte (TMAH solution). The TMAH solution thus obtained induces corrosion of the aluminium interconnection which is formed on semiconductor substrates. This phenomenon causes serious deterioration of semiconductor devices.

To avoid the corrosion, one method has been proposed, which uses a cell equipped with double exchange-membranes. ${ }^{5)}$ In this method, 
the cell almost completely inhibits the permeation of chlorine and chloride ion into the catholyte (TMAH solution). But the complexity of the apparatus and the high electric voltage are problems, and nevertheless, the problem of corrosion of the cell by generated chlorine and chloride ion still remains.

So, for avoiding the corrosion, a less corrosive organic ester, inethyl formate, ${ }^{6,7)}$ and the least corrosive inorganic ester, dimethyl carbonate, $8,9,10$ ) were used for the synthesis of a chloride-free TMAH solution, instead of methyl chloride.

\section{SYMTHESIS OF TETRAMETHYLAMMONIUM FORMATE (TMAF)}

It has been reported that a rate of methylation of trimethylamine with methyl carboxylate to tetramethylammonium ion is dependent on the strength of the acid. ${ }^{11)}$ For the synthesis of pure TMAH solution free from a chloride ion, methyl formate $\underline{5}$ was used as a reagent for methylation of trimethylamine $\underline{2}$, instead of methyl chloride $\underline{3}$ (Scheme 2).

$$
\begin{gathered}
\underline{2}+\underset{\underline{5}}{\mathrm{HCOOCH}_{3}} \stackrel{\text { heat }}{\mathrm{CH}_{3} \mathrm{OH}} \underset{3}{\longrightarrow}\left(\mathrm{CH}_{3}\right)_{4} \mathrm{~N}^{+} \mathrm{HCOO}^{-} \\
\underline{6}+\mathrm{H}_{2} \mathrm{O} \stackrel{\mathrm{e}^{-}}{\longrightarrow} \underline{1}+1 / 2 \mathrm{HCOOH}+1 / 2 \mathrm{CO}_{2}+1 / 2 \mathrm{H}_{2}
\end{gathered}
$$

Scheme 2

All of the starting materials were used after being distilled with quartz apparatuses and stored in polyethylene bottles.

Tetramethylammonium formate (TMAF) $\underline{6}$ was prepared in a $3000 \mathrm{ml}$ stainless autoclave by dissolving $470 \mathrm{~g}(8.0 \mathrm{~mol})$ of 2 and $720 \mathrm{~g}(12.0$ mol) of 5 in $800 \mathrm{~g}$ of methanol which was cooled with ice-water, and thein heated. After cooling, the resulting mixture was removed into a $3000 \mathrm{ml}$ quartz flask, and then evaporated to dryness, forming a white residue of 6 . The yield of this reaction was detected as follows. About $4 \mathrm{~g}$ of the white residue of 6 was dissolved in $50 \mathrm{ml}$ purified water, and the formate was converted to TMAH 1 with $100 \mathrm{ml}$ of an anion-exchange resin (DOWEX, SBR-P) This

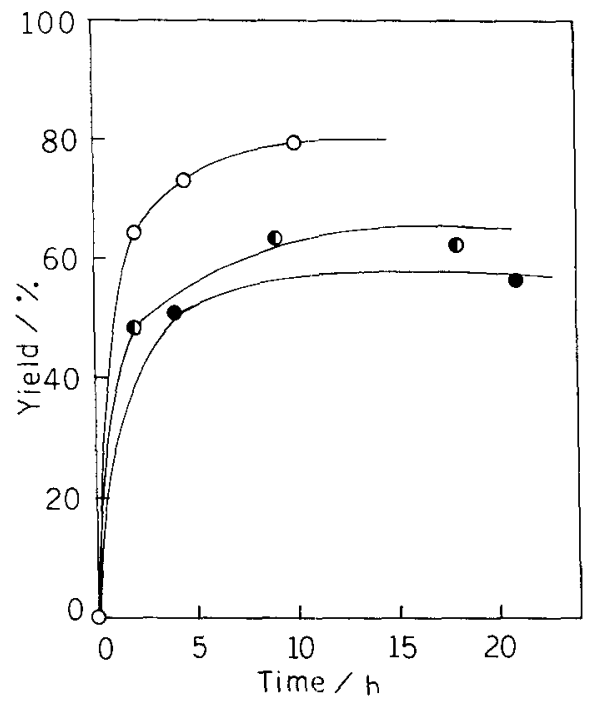

Fig.1 Effect of reaction temperature on yield in TMAF 6 synthesis: (O) $115^{\circ} \mathrm{C}$, (D) $127^{\circ} \mathrm{C}$, and (0) $131^{\circ} \mathrm{C}$.

TMAH solution was titrated with $1 \mathrm{M} \mathrm{HCl}$ standard solution using phenolphthalein as an indicator.

The reaction of $\underline{2}$ and $\underline{5}$ was examined at 115,127 , and $131^{\circ} \mathrm{C}$. The yield of the reaction is shown in Fig.1. A good yield was obtained after $10 \mathrm{~h}$, when the reaction was operated at $131^{\circ} \mathrm{C}$.

The pressure of the reaction is shown in Fig.2. The pressure increased rapidly at the beginning of the reaction for the sake of heat evolutions, and decreased slowly with consumption of the starting materials, especially trimethylamine $\underline{2}$. Then, a gradual increase of the pressure was observed. This revealed the decomposition of the starting materials or the reaction products. There was CO gas in the autoclave at the end of the reaction. No decomposition products were obtained, when the reaction product $\underline{6}$ was dissolved in methanol, and then was heated at the same temperature. This indicates the decomposition of methyl formate $\underline{5}$, which generates $\mathrm{CO}$ gas as shown in Eq.1.

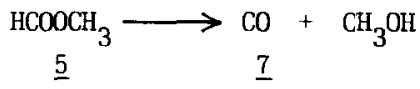




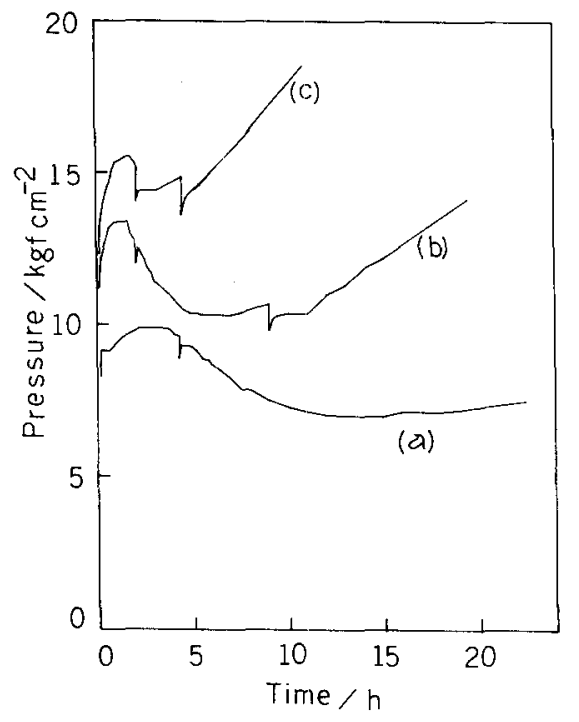

Fig.2 Relationship between reaction time and observed pressure in TMAF $\underline{6}$ synthesis: (a) 115 ${ }^{\circ} \mathrm{C}$, (b) $127^{\circ} \mathrm{C}$, and (c) $131^{\circ} \mathrm{C}$.

If a much higher temperature was used in this synthesis, the decomposition of $\underline{5}$ must be accelerated, forming a larger volume of $\mathrm{CO}$ gas, which makes the operation of the reaction dangerous. This white residue $\underline{6}$ was electrolyzed without further purification.

\section{SYNTHESIS OF TETRAMETHYLAMMONIUM HYDROXIDE SOLUTION BY ELECTROLYSIS OF ITS FORMATE}

An electrolytic cell consisting of a polypropylene anodic chamber equipped with an $\mathrm{IrO}_{2}$ coated $\mathrm{Ti}$-plate anode and a cathodic one with a cathode of stainless steel (SUS 304) was used. An ion exchange membrane (Du Pont, Nafion $324^{12)}$ ) separated these chambers. A solution of $286 \mathrm{~g}(2.25 \mathrm{~mol})$ of $\underline{6}$ in $360 \mathrm{~g}$ purified water was added into a $1000 \mathrm{ml}$ polyethylene bottle, and circulated through the anodic chamber. Similarly, $240 \mathrm{~g}$ purified water in the presence of a small amount of TMAH as an electrolyte was added into another polyethylene bottle, and circulated through the cathodic chamber. Electrolysis was performed by impressing $20 \mathrm{~V}$ between the anode and the cathode for $15 \mathrm{~h}$ to give $610 \mathrm{~g}$ of $30.1 \% \mathrm{TMAH}$ solution. The charge of the electrolysis was $3.14 \mathrm{~F}$.

The vigorous generation of $\mathrm{CO}_{2}$ gas was

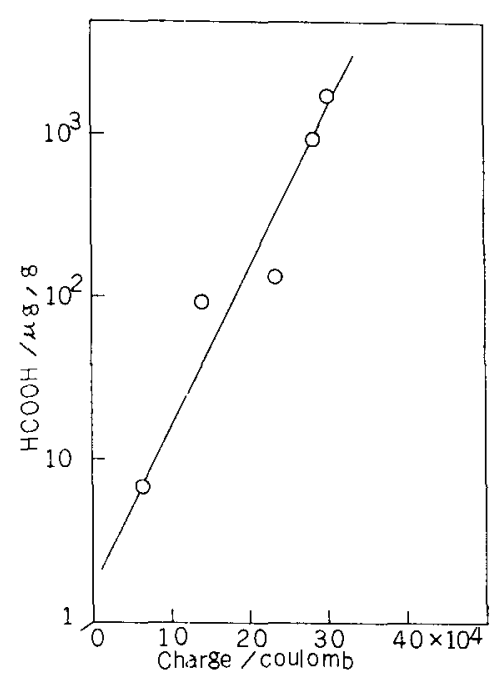

Fig. 3 Formate ion migration to the catholyte in electrolysis of TMAF $\underline{6}$.

observed in the anodic chamber. It was reported that $\mathrm{HCOOH}$ was electrolyzed to $\mathrm{CO}_{2}$ with about $100 \%$ current efficiency at a $\mathrm{Pt}$ electrode in acidic condition $\left(\mathrm{E}^{\mathrm{O}}=-0.196 \mathrm{~V}\right)$ (Eq. 2) .13)

$\mathrm{HCOOH} \longrightarrow \mathrm{CO}_{2}+2 \mathrm{H}^{+}+2 \mathrm{e}^{-}$

The mechanism is shown in Scheme $3 .^{14)}$

$\mathrm{HCOOH} \longrightarrow \mathrm{HCOOH}$ (a) (fast)

$\mathrm{HCOOH} \mathrm{(a)} \longrightarrow \mathrm{COOH}$ (a) $+\mathrm{H}^{+}+e^{-}$(slow)

$\mathrm{COOH}$ (a) $\longrightarrow \mathrm{CO}_{2}+\mathrm{H}^{+}+\mathrm{e}^{-}$(fast)

(a); in adsorption.

Scheme 3

Since HCOOH was not perfectly electrolyzed under the conditions of the present study, half of it remained in the anolyte (scheme 2), and a small amount of it migrated into the catholyte. The migration through the membrane is shown in Fig.3. Its concentration was more than 1000 ppm at the end of the electrolysis.

\section{SYNTHESIS OF TETRAMETHYLAMYNIUM HYDROGEN- CARBONATE (TMAC)}

Synthesis of TMAH solution from $\underline{6}$ has a problem of the contamination of formic acid into the catholyte. In this section, we would 
Table 1 Reaction of $\underline{2}^{\text {a) }}$ and $\underline{8}^{\text {b) }}$ at a ratio of 2 . Run Solvent ${ }^{\mathrm{c})}$ Time(h) Temp $\left({ }^{\circ} \mathrm{C}\right)$ Yield from $\underline{2}(\%)$

\begin{tabular}{lcrll}
1 & $\mathrm{CH}_{3} \mathrm{OH}$ & 5.5 & 144 & 47.7 \\
2 & $\mathrm{CH}_{3} \mathrm{OH}$ & 5.5 & 165 & 43.7 \\
3 & $\mathrm{C}_{6} \mathrm{H}_{6}$ & 5.0 & 171 & 40.0 \\
4 & $\mathrm{CH}_{3} \mathrm{CN}$ & 5.0 & 171 & 37.7 \\
5 & $\mathrm{CH}_{3} \mathrm{OC}_{2} \mathrm{H}_{5} \mathrm{OH}$ & 5.0 & 140 & 44.5 \\
6 & $\mathrm{C}_{2} \mathrm{H}_{5} \mathrm{OC}_{2} \mathrm{H}_{5} \mathrm{OH}$ & 5.0 & 143 & 42.1 \\
7 & $\mathrm{MIBK}^{\mathrm{N}}$ & 5.0 & 143 & 43.9 \\
8 & - & 5.0 & 135 & 37.8 \\
\hline
\end{tabular}

a) $208 \mathrm{~g}$. b) $159 \mathrm{~g}$. c) $200 \mathrm{~g}$. d) Isobuthyl methyl ketone. e) No solvent.

Table 2 Dissociation constants at $25^{\circ} \mathrm{C}$.

\begin{tabular}{lcc}
\hline Compound & Dissociation stage & pKa \\
\hline $\mathrm{HCOOH}$ & 1 & 3.757 \\
$\mathrm{H}_{2} \mathrm{CO}_{3}$ & 2 & 6.35 \\
& & 10.33 \\
\hline
\end{tabular}

like to report a preparation of further purified TMAH solution by using dimethyl carbonate as a reagent (Scheme 4).

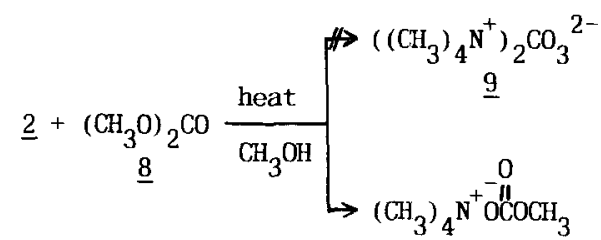

$$
\begin{aligned}
& 10 \\
& \underline{10}+\mathrm{H}_{2} \mathrm{O} \stackrel{\text { heat }}{\longrightarrow}\left(\mathrm{CH}_{3}\right)_{4} \mathrm{~N}^{+-"} \mathrm{O} \\
& 11 \\
& \begin{aligned}
\underline{11}+\mathrm{H}_{2} \mathrm{O} \stackrel{\mathrm{e}^{-}}{\rightarrow}\left(\mathrm{CH}_{3}\right){ }_{4} \mathrm{~N}^{+} \mathrm{OH}^{-}+\mathrm{CO}_{2}+1 / 2 \mathrm{H}_{2} \\
\underline{1}+1 / 4 \mathrm{O}_{2}+1 / 2 \mathrm{H}_{2} \mathrm{O}
\end{aligned}
\end{aligned}
$$

Scheme 4

We tried to make tetramethylammonium carbonate $\underline{9}$ by reaction of trimethylamine $\underline{2}$ and dimethyl carbonate $\underline{8}$ at a ratio of 2 in the same manner as described in the case of the
Table 3 Reaction of $\underline{2}^{\mathrm{a})}$ and $\underline{8}^{\mathrm{b})}$ at a ratio of 1 . Run Solvent ${ }^{\mathrm{c})}$ Time(h) Temp $\left({ }^{\circ} \mathrm{C}\right)$ Yield from $\underline{2}(\%)$

\begin{tabular}{rrrrr}
1 & $\mathrm{CH}_{3} \mathrm{OH}$ & 7.5 & 78 & 64.4 \\
2 & $\mathrm{CH}_{3} \mathrm{OH}$ & 5.5 & 113 & 91.2 \\
\hline
\end{tabular}

a) $104 \mathrm{~g}$. b) $159 \mathrm{~g}$. c) $200 \mathrm{~g}$.

formate. The results are shown in Table 1 . The results show that $\underline{2}$ and $\underline{8}$ reacted in an equivalent molecular ratio and one of two methoxy groups of $\underline{8}$ was incorporated into $\underline{9}$. The reason for this difference of reactivity of the two methoxy groups of $\underline{8}$ is a distinction of dissociation constants of carbonic acids. The dissociation constants of formic and carbonic acid are shown in Table 2. ${ }^{15)}$ The value of the second dissociation stage of carbonic acid shows the weaker methylation ability of one of the two methyl groups of dimethyl carbonate than the other, accordingly one of the two methoxy groups was incorporated into $\underline{9}$. The results of the reaction of trimethylamine and dimethyl carbonate in an equivalent molecular ratio are shown in Table 3. Tetramethylammonium methylcarbonate 10 was effi ciently obtained at $113^{\circ} \mathrm{C}$ for $5.5 \mathrm{~h}$. The relationship between reaction time and yield is show in Fig. 4. The reaction was almost finished at $120{ }^{\circ} \mathrm{C}$ for about $4 \mathrm{~h}$. The methylcarbonate $\underline{10}$ thus obtained was dissolved in purified water, and heated to hydrolyze. Removal of resultant methanol provided hydrogencarbonate salt (TMAC) 11 (11: ${ }^{13} \mathrm{C}$ NMR $\left(\mathrm{D}_{2} \mathrm{O}\right) 57.5\left(\mathrm{CH}_{3}\right)$ and $\left.162.7\left(\mathrm{HCO}_{3}\right) \mathrm{ppm}\right)$.

\section{SYNIHESIS OF TETRAMETHYLAMMONIUM HYDROXIDE SOLITTION BY ELECTROLYSIS OF ITS HYDROGENCARBONATE}

The TMAC solution obtained above was electrolyzed to a TMAH solution in the same manner as described in the case of the formate. A 63.0\% solution of TMAC (482 $\mathrm{g}-2.25 \mathrm{~mol})$ in $120 \mathrm{~g}$ purified water was reserved in a $1000 \mathrm{ml}$ polyethylene bottle, and was circulated through an anodic chamber. In the same manner, $240 \mathrm{~g}$ purified water containing a small amount of TMAH as an electrolyte was circulated through a 


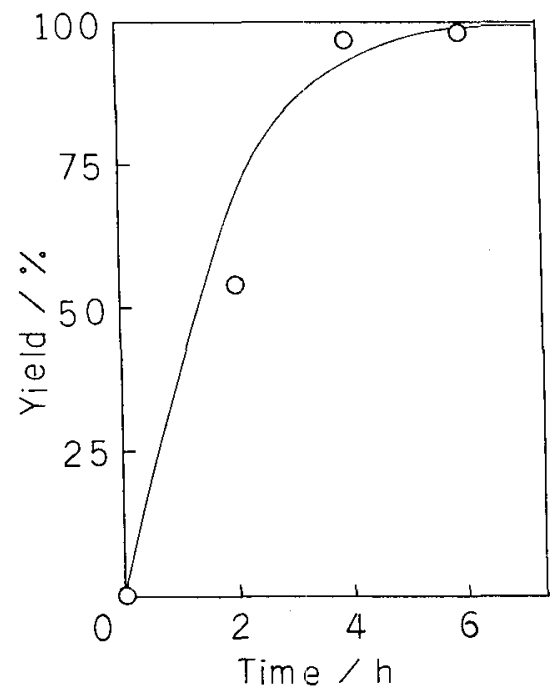

Fig.4 Relationship between reaction time and yield in synthesis of TMIAC $\underline{10}$ from $\underline{2}$ and $\underline{8}$ at a ratio of 1 at $120^{\circ} \mathrm{C}$.

cathodic chamber. Electrolysis was performed by impressing $20 \mathrm{~V}$ for $12 \mathrm{~h}$ to give $626 \mathrm{~g}$ of a 30.7\% ТМAH solution without loss of current efficiency (Fig.5). The vigorous generation of $\mathrm{CO}_{2}$ gas was observed in the anodic chamber similar to the case of the formate.

It is well known that electrolysis of a chloride salt in the conventional manner gives rise to gradual decrease of current efficiency. ${ }^{16)}$ This phenomenon is attributed to a degeneration of the ion exchange membrane (Nafion membrane). Seko, ${ }^{17)}$ and Lowry and Maurits ${ }^{18)}$ explained this degeneration based on the fact that the base-resin of Nafion has a non-bridged skeleton structure, and the development of a cation cluster of large volume around the sulfonate groups modifies the skeletal structure of the Nafion membrane.

This skeletal modification produces more hydrophilic domain in the membrane, and part of a hydroxide ion in the catholyte, which is originally prevented to penetrate by the electric field of sulfonate ions, moves into the anolyte to cause the decrease of current efficiency.

Fortunately, the electrolysis of TMAC efficiently produced TMAH without loss of current efficiency. Now we electrolyzed a

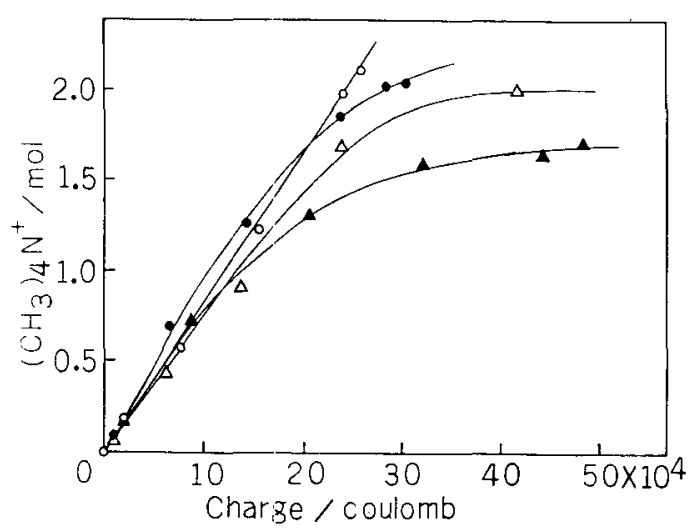

Fig. 5 Tetramethylammonium ion migration and consumed charge in impressing $20 \mathrm{~V}:(\mathrm{O})$ hydrogencarbonate, $(\bullet)$ formate, $(\Delta)$ chloride, and (\) sulfate.

variety of tetramethylammonium salts and studied the effect of anions on the current efficiency to clear whether the phenomenon is limited to a chloride ion or not.

The experiments were carried out in the following manner. A solution (484 g) containing $2.25 \mathrm{~mol}$ of TMAC solution obtained above was neutralized by the addition of $113 \mathrm{~g}$ of $98 \%$ sulfuric acid (1.13 mol), $104 \mathrm{~g}$ of formic acid $(2.26 \mathrm{~mol})$, or $228 \mathrm{~g}$ of $36 \%$ hydrochloric acid (2.25 mol). The solution was electrolyzed in the same manner as described above. The migration of the tetramethylammonium ion $\left(\left(\mathrm{CH}_{3}\right) 4^{\mathrm{N}^{+}}\right.$) was monitored by the titration of the catholyte with $0.1 \mathrm{M}$ HCl solution using phenolphthalein as an indicator.

The correlation between the amount of the migrated tetramethylammonium ion and the consumed charge is shown in Fig.5. A substantial decrease of the current efficiency was seen in the latter half period of the electrolyses of sulfate, chloride, and formate salts. However, we could see no decrease of current efficiency with the hydrogencarbonate salt, and the linear relationship between the migrated ammonium ion and the consumed charge was maintained until the final stage. We justified these results as follows. When the chloride salt was electrolyzed, $\mathrm{HClO}$ and $\mathrm{HCl}$ were generated in the anolyte, in addition to molecular chlorine $\left(\mathrm{Cl}_{2}\right)$ (Eq.3). In the same 
Table 4 Typical analytical results of impurities in $30.7 \%$ TMAH solution ${ }^{\text {a) }}$.

\begin{tabular}{lrrrrrrrrrr} 
Element & $\mathrm{Na}$ & $\mathrm{Ca}$ & $\mathrm{Al}$ & $\mathrm{Fe}$ & $\mathrm{Cr}$ & $\mathrm{Ni}$ & $\mathrm{Mg}$ & $\mathrm{Mn}$ & $\mathrm{Zn}$ & $\mathrm{Cu}$ \\
Content (ppb) & 5 & 2 & 2 & 4 & $<1$ & $<1$ & $<1$ & $<1$ & $<1$ & $<1$ \\
\hline
\end{tabular}

a) Detected by graphite furnace atomic absorption spectrometry.

manner, the sulfate salt and the formate salt produced sulfuric acid and formic acid (Eqs.4-5), respectively .

$$
\begin{aligned}
& \mathrm{Cl}^{-}+1 / 2 \mathrm{H}_{2} \mathrm{O}-\mathrm{e}^{-} \rightarrow 1 / 2 \mathrm{HCl}+1 / 2 \mathrm{HClO} \\
& \mathrm{SO}_{4}{ }^{2-}+\mathrm{H}_{2} \mathrm{O}-2 \mathrm{e}^{-} \rightarrow 1 / 2 \mathrm{O}_{2}+\mathrm{H}_{2} \mathrm{SO}_{4} \\
& \mathrm{HCOO}^{-}-\mathrm{e}^{-} \rightarrow 1 / 2 \mathrm{HCOOH}+1 / 2 \mathrm{CO}_{2} \\
& \mathrm{HCO}_{3}{ }^{-}-\mathrm{e}^{-} \rightarrow \mathrm{CO}_{2}+1 / 4 \mathrm{O}_{2}+1 / 2 \mathrm{H}_{2} \mathrm{O}
\end{aligned}
$$

The electrolysis of TMAC, however, produced no strongly acidic material (Eq.6). The acidity of the anode side increased by the progress of the electrolysis of the salts other than TMAC. As a result, the hydroxide ion in the catholyte became able to migrate to the anolyte through the membrane which took the relaxed structure as mentioned earlier.

We must also consider the fact that the hydrogen ion transfer from the anolyte to the catholyte on the increase of hydrogen ion concentration. On the other hand, the basic condition $(\mathrm{pH}=9-10)$ was kept in the anolyte at the electrolysis of TMAC, so that it was difficult for the hydroxide ion in the catholyte to migrate through the membrane to the anolyte for the repulsion of the hydroxide ion in the anolyte, and no decrease in the current efficiency was observed.

As seen in Fig.5, the decrease in the current efficiency is more prominent with the stronger acid formed in the anolyte, and it is realized that the important factor controlling the current efficiency is $\mathrm{pH}$ of the anolyte.

The 30.7\% TMAH solution prepared by the TMAC method contained a much lower ammount of metallic ions ( $<10 \mathrm{ppb}$ ) (Table 4 ) than that by other methods. The concentration of carbone dioxide of this solution was less than $10 \mathrm{ppm}$.

\section{CONCIUSION}

The new process of synthesizing a purified TMAH solution by using hydrogencarbonate as an intermediate has a lot of benefits such as having a good yield of the reaction of trimethylamine and dimethyl carbonate, no corrosive anions in the TMAH solution, little contamination of a carbonate ion into the catholyte for the sake of its low concentration in the anolyte, and no decrease of current efficiency, because of the basic condition of the anolyte in electrolysis.

More purified TMAH solution was obtained with the hydrogencarbonete as an intermediate. Trimethylamine and dimethyl carbonate reacted in an equivalent molecular ratio, suggesting that one of the two methyl groups of dimethyl carbonate was incorporated into the methyl carbonate salt. Electrolysis of the hydrogencarbonate solution which was free from methanol by hydrolyzing of the methyl carbonate salt gave the corresponding TMAH solution with a high current efficiency. A sufficient current efficiency was obtained, when hydrogencarbonate was used as a counter anion of a tetramethylammonium cation. The decrease of current efficiency was more prominent with stronger acids in the anolyte. It was suggested that the important factor affecting current efficiency was pH of the anolyte.

\section{REFEREKCES}

1) W.K.Musker, J. Am. Chem. Soc., 86, 960 (1964) .

2) H.Nakane, A.Yokota, and S.Asaumi, J. Synth. Org. Chem. Jpn., 42, 979 (1984).

3) H.Matsuzaki, Semiconcluctor World, (No.12) 116 (1991).

4) H.Harada, Japan Kokai Tokkyo Koho, 57-181385 (1982).

5) H.Iwamoto and T.Sata, Japan Kokai Tokkyo 
Koho, H2-115387 (1990).

6) 0.Yagi and S.Shimizu, Denki Kagaku, 61, 443 (1993).

7) 0.Yagi and S.Shimizu, Nippon Kagaku Kaishi, 1993, 291.

8) 0.Yagi and S.Shimizu, Chem. Lett., 1993 , 2041.

9) 0.Yagi and S.Shimizu, Chem. Lett., 1994, 1683.

10) O.Yagi and S.Shimizu, Nippon Kagaku Kaishi, 1995, 74 .

11) L.P.Hammett and H.L.Pfluger, J. Am. Chem. Soc., 포, 4079 (1933).
12) W.Grot, Chem. -Ind. -Tech., 50, 299 (1978).

13) K.Shimazu and H.Kita, Denki Kagaku, $\underline{53}, 854$ (1985).

14) K.Fujikawa and K.Takeya, Denki Kagaku, 6므, 557 (1992).

15) "Kagaku Binran", 3rd ed. by Nippon Kagaku Kai, (1984) p.338.

16) "Denki Kagaku Binran”, 4th ed. by Denki Kagaku Kyokai, (1985) p.286.

17) M.Seko, Ind. Eng. Chem., Prod. Res. Dev., 15, $286(1976)$.

18) S.R.Lowry and K.A.Maurits, J. An. Chem. Soc., $\underline{102}, 4665$ (1980). 